\title{
Baggio, R. \& J. Klobas (2011) Quantitative Methods in Tourism: A Handbook. Aspects of Tourism Series. Channel View Publications. ISBN 978-1-84541-173-2, 225 pp.
}

\author{
Reviewed by Miroslava Dimitrova ${ }^{1}$
}

Received: $10 / 08 / 2011$

\begin{abstract}
${ }^{1}$ Department of Tourism, International University College, 3 Bulgaria str., 9300 Dobrich, Bulgaria; tel: +359 58 655630; e-mail: miroslava.dimitrova@vumk.eu
\end{abstract}

(C) 2011 International University College. All rights reserved

Citation: Baggio, R. \& J. Klobas (2011) Quantitative Methods in Tourism: A Handbook. Aspects of Tourism Series. Channel View Publications. ISBN 978-1-84541-173-2, 225 pp., Reviewed by Miroslava Dimitrova, European Journal of Tourism Research 4(2), pp. 251-252

Tourism subject is often underestimated and its scientific importance is neglected mainly because papers in tourism are predominantly descriptive and statistical methods they rely on are usually limited to some basic formulae and calculations. Yet researchers' interest in tourism as an important business activity is growing and so the approach to tourism subject evolves. The Handbook of Baggio and Klobas is a reflection to this trend providing a variety of quantitative methods in statistics that tourism experts could apply.

The book is divided into two parts. Part 1: The Analysis of Data consists of introduction and five chapters that cover topics from the very basics of data collection through model building to time series analysis and forecasting.

Chapter 1: The Nature of Data in Tourism, gives a brief overview on the types and forms of data with a special emphasis on the quality of data. A useful list of sources of secondary tourism data is included.

Chapter 2: Testing Hypothesis is dedicated to the most commonly used statistical hypothesis tests. Other issues such as statistical power and effect size, sample size and significance are also included, as well as the bootstrap method and meta-analysis which are used to improve outcomes' reliability.

Chapter 3: Data Analysis discusses techniques such as factor analysis, cluster analysis, multidimensional scaling techniques. The above mentioned are elaborated in details and many real-life cases and applications to papers in tourism are given as examples.

Chapter 4: Model Building as the title suggests gives an in-depth overview of regression and structural equation modelling. Special attention is paid to logistic regression as particularly pertinent to tourism research purposes. Interesting evidences for so-called "pitfalls for impatient modellers" are given (such as Anscome quartet).

Chapter 5: Time dependant phenomenon and forecasting deals with time series analysis and its implementation to predict various behavioural patterns in tourism (ex.: tourist arrivals). Others related issues discussed here 
Baggio, R. \& J. Klobas (2011) Quantitative Methods in Tourism: A Handbook. Aspects of Tourism Series. Channel View Publications. ISBN 978-1-84541-173-2, 225 pp., Reviewed by Miroslava Dimitrova,

European Journal of Tourism Research 4(2), pp. 251-252

are stationarity and stability of the system, predictability, non-linearity etc.

Part 2: Numerical methods is logically following the techniques described in Part 1. According to the author, they are quite simple as methodology, but require complex calculation with higher degree of computer computation intensiveness. These methods are discussed in three consecutive chapters as follows: Chapter 6: Maximum Likelihood Estimation; Chapter 7: Monte Carlo Methods and Chapter 8: Agentbased Modelling and Simulations.

The authors' mathematic expertise is evident by the style of writing and systematic explanations. In the book they start with the main concept of a given statistical method and apply it to tourism purposes by various techniques taken from real research papers in tourism. Though they claim in the beginning that the number of calculation is reduced to minimum so that the reader won't be scared, there is still quite a big portion of mathematics involved. Yet-everything is clarified and visualized with graphs, charts and tables contributing further to better understanding.
Application to real cases is a culmination and usually at that point even the amateur in statistics could grasp the overall idea. It is advisable, though, that potential reader has at least some basic knowledge in statistics and mathematics. This is why researchers, graduate and $\mathrm{PhD}$ students will be most likely the target audience.

Unlike other books on this subject, Quantitative Methods in Tourism does not focus on theoretical discussion on presented techniques. It is therefore quite practical and could be successfully used either as a textbook (as an overview of different statistical methods) or as a reference (for more detailed explanation of a particular technique).

As a conclusion, this book provides practical tools for quantitative analysis of data in tourism. It could definitely improve the quality and reliability of any research or at least give some inspirational insights on plethora of methods in statistic that could be applied in tourism analysis. 